\title{
Determination of NTPase activities from measurement of true inorganic phosphate in the presence of labile phosphate compounds
}

Faith E. H. Katz ${ }^{1}$, Xinying Shi', Cedric P. Owens ${ }^{1,2}$, Simpson Joseph ${ }^{1}$, and F. Akif Tezcan ${ }^{1 *}$

${ }^{1}$ Department of Chemistry and Biochemistry, University of California, San Diego, La Jolla, California, 92039, United States

${ }^{2}$ Current Address: College of Science and Technology, Chapman University, One University Dr. Orange, California, 92866, United States

nitrogenase, EF-G, ribosome, inorganic phosphate, nucleotide hydrolysis, phosphomolybdate inorganic phosphate $\left(\mathrm{P}_{i}\right)$

organic phosphate compound (OPC)

elongation factor $\mathrm{G}$ (EF-G)

high-performance liquid chromatography (HPLC)

MoFe-protein (MoFeP)

Fe-protein (FeP)

electron $\left(\mathrm{e}^{-}\right)$

electron transfer (ET)

phosphocreatine (PC)

ethylenediaminetetraacetic acid (EDTA)

sodium dodecyl sulfate (SDS)

gas chromatography (GC)

deionized (DI)

thin-layer chromatography (TLC)

wild-type (wt)

percent relative standard deviation (\%RSD)

\section{ABSTRACT}

One of the most common assays for NTPase activity entails the quantification of inorganic phosphate $\left(\mathrm{P}_{i}\right)$ as a colored phosphomolybdate complex at low $\mathrm{pH}$. While this assay is very sensitive, it is not selective for $P_{i}$ in the presence of labile organic phosphate compounds (OPCs). Since NTPase activity assays typically require a large excess of OPCs, such as nucleotides, selectivity for $P_{i}$ in the presence of OPCs is often critical in evaluating enzyme 
activity. Here we present an improved method for the measurement of enzymatic nucleotide hydrolysis as $\mathrm{P}_{i}$ released, which achieves selectivity for $\mathrm{P}_{i}$ in the presence of OPCs while also avoiding the costs and hazards inherent in other methods for measuring nucleotide hydrolysis. We apply this method to the measurement of ATP hydrolysis by nitrogenase and GTP hydrolysis by elongation factor $\mathrm{G}$ (EF-G) in order to demonstrate the broad applicability of our method for the determination of nucleotide hydrolysis in the presence of interfering OPCs.

\section{INTRODUCTION}

Throughout biology, nucleoside triphosphate (NTP: ATP or GTP) hydrolysis is used to drive cellular processes such as chemical transformations, protein motion, and signaling [1-3]. A thorough mechanistic understanding of such ATP/GTP-driven processes requires a reliable means to quantify nucleotide hydrolysis under dynamic conditions in complex, multi-component media. Many assays have been developed to measure ATP/GTP hydrolysis, which focus on monitoring the amount of a) ADP/GDP formed [4,5] or b) inorganic phosphate $\left(P_{i}\right)$ released $[6,7]$ during the course of a reaction. In the case of the former, assays typically require separation of nucleoside diphosphate species formed from unused nucleoside triphosphate species by highperformance liquid chromatography (HPLC) [5]. In the case of the latter, $\mathrm{P}_{i}$ can be reacted with molybdic acid to yield a colored product, [6] or radioactive ${ }^{32} \mathrm{P}_{i}$ can be measured with a phosphorimager [4]. However, these assays often measure total phosphate content of the reaction mixture rather than true $P_{i}$ released from enzymatic nucleotide hydrolysis, which can lead to substantial error in measurements of ATP/GTP hydrolysis activities [6,7]. Thus, there is an outstanding need to develop analytical methods for quantifying nucleotide hydrolysis that achieve the precision of chromatographic methods while maintaining the simplicity of colorimetric methods and are compatible with the multi-component composition of complex biochemical reactions.

Our interest in developing an improved assay for nucleotide hydrolysis is based on our work with nitrogenase $[8,9]$, which catalyzes such a complex, ATP-driven biochemical reaction, namely the reduction of atmospheric $\mathrm{N}_{2}$ into $\mathrm{NH}_{3}$ [10]:

$$
\mathrm{N}_{2}+8 \mathrm{e}^{-}+8 \mathrm{H}^{+}+16 \mathrm{ATP} \rightarrow 2 \mathrm{NH}_{3}+\mathrm{H}_{2}+16 \mathrm{ADP}+16 \mathrm{P}_{i}(\text { Equation 1) }
$$

Nitrogenase consists of two component proteins. The catalytic component of nitrogenase, MoFe-protein (MoFeP), is an $\alpha_{2} \beta_{2}$ heterotetramer that contains the site of $N_{2}$ binding and reduction, the so-called FeMo-cofactor [11]. The other component, Fe-protein (FeP), is a homodimeric ATPase that couples the hydrolysis of two ATP molecules to the transfer of an electron $\left(\mathrm{e}^{-}\right)$to MoFeP. After each interprotein electron transfer (ET) event, oxidized ADP-bound 
FeP dissociates from MoFeP [12], followed by ADP/ATP exchange and re-reduction of FeP for the next cycle. Per Equation 1, this association/dissociation cycle must occur eight times for every $\mathrm{N}_{2}$ reduced. It is important to note that both ATP hydrolysis by FeP and catalysis by MoFeP require the presence of both protein components: FeP by itself has no intrinsic ATPase activity [13] and MoFeP by itself cannot reduce $\mathrm{N}_{2}$ [14]. ADP is a strong inhibitor of nitrogenase activity, not only because it binds more tightly to FeP than ATP, but also because ADP-bound FeP can compete with ATP-bound FeP for interacting productively with MoFeP [15]. Thus, standard nitrogenase activity assays require an ATP-regeneration system consisting of phosphocreatine (PC) and creatine kinase to continuously convert ADP to ATP and sustain enzymatic turnover [14]. Creatine kinase catalyzes the transfer of the phosphate group of PC to ADP to regenerate ATP and also produce creatine. The resulting mixture of multiple phosphatecontaining species and their dynamic interconversions renders the quantification of ATP hydrolysis challenging, as discussed below.

While enzymatic ATP hydrolysis is routinely measured as the amount of ADP formed using reverse-phase HPLC to separate the nucleoside diphosphates from nucleoside triphosphates [16-18], when this strategy is applied to measure nitrogenase ATPase activity, the ATP-regeneration system must be omitted. Thus, the ATPase activity of nitrogenase is determined under conditions where inhibition by ADP becomes a concern [19]. Furthermore, baseline separation of ATP and ADP by HPLC takes at least several minutes to achieve for each data point, limiting the number of assays that can be performed in one day. Lastly, HPLC analysis generates a large volume of hazardous organic waste.

One way to measure ATP hydrolysis by nitrogenase in the presence of the ATPregeneration system, which allows nitrogenase to be fully active as discussed above, is to colorimetrically determine the amount of creatine produced by enzymatic cleavage of PC in the regeneration of ATP [20]. However, this colorimetric method suffers from interference by excess PC and some nitrogenase substrates such as hydrazine [21]. To circumvent these interferences, individual activity assay solutions must be subjected to ion exchange chromatography [21], limiting the number of assays that can be performed in one day. Additionally, this technique is only useful in experiments utilizing the PC/kinase ATPregeneration system, thus it is not broadly applicable to the study of NTPases.

Finally, nitrogenase ATPase activity can be evaluated as $P_{i}$ released using a colorimetric method in which $\mathrm{P}_{i}$ is reacted with molybdic acid at low $\mathrm{pH}$ to form a colored complex. Nearly a century ago, Fiske and Subbarow [22] popularized this method of phosphate analysis, and their paper was recently listed as \#37 of the top 100 most cited papers of all time [23]. This 
colorimetric method was initially developed to measure total phosphate content in blood and tissue, and it was desirable to work at low $\mathrm{pH}$ in order to catalyze the hydrolysis of organic phosphate compounds (OPCs) in the analyte such as nucleotides. However, the acidic conditions of this procedure are not conducive to the analysis of nucleotide hydrolysis in enzymatic assays including nitrogenase, since routine assays require the determination of true $\mathrm{P}_{i}$ in the presence of a large excess of OPCs. Additionally, it has been demonstrated that molybdate itself can accelerate the hydrolysis of OPCs [24].

Many attempts have been made to address the interference caused by OPCs in the colorimetric determination of $\mathrm{P}_{i}$ as a phosphomolybdate complex, including color development at substantially lower temperatures [25], in organic solvent [26], for shorter periods of time [27], and with increasing amounts of molybdic acid [28]. In some protocols, the phosphomolybdate complex is quickly extracted in alcohol before acidic conditions cause appreciable hydrolysis of labile OPCs in the analyte [29,30]. While these methods can improve the selectivity of the phosphomolybdate assay for $\mathrm{P}_{i}$, they often decrease simplicity, while increasing time and cost. Here, we have adapted the colorimetric determination of $\mathrm{P}_{i}$ as a blue, phosphomolybdate complex for measuring ATPase activity by nitrogenase in a way that maximizes both precision and simplicity and is also more broadly applicable to the measurement of NTPase activity.

Inspired by additional work from Fiske and Subbarow, in which they achieved the first purification of $\mathrm{PC}$ by precipitating $\mathrm{P}_{i}$ as a $\mathrm{Ca}^{2+}$ salt to remove $\mathrm{P}_{i}$ from preparations of $\mathrm{PC}$ [31], we decided to separate true $\mathrm{P}_{i}$ from OPCs prior to reaction with molybdic acid in a similar way. This strategy has been used to measure acetyl phosphate content in enzyme preparations [32] and true $\mathrm{P}_{i}$ content in frog muscle [33], but it has never been applied to the study of enzymatic nucleotide hydrolysis activity.

We reasoned that this strategy had not been adapted for NTPase activity measurements because enzyme assays are typically stopped by addition of a strong acid, which will cause the hydrolysis of OPCs to begin even before the acidic color reagent is added. Furthermore, if the $\mathrm{Ca}^{2+}$ precipitation strategy is to be utilized, ethylenediaminetetraacetic acid (EDTA), since it chelates $\mathrm{Ca}^{2+}$, cannot be used to quench enzyme activity, nor can sodium dodecyl sulfate (SDS) [28], as it interferes with subsequent phosphomolybdate complex formation. However, substrate reduction by nitrogenase depends on electrostatic interactions between FeP and MoFeP to facilitate each ET cycle [9], and a large enough excess of salt ions fully inhibits activity [34]. As many other NTPase activities involve electrostatic interactions with protein partners [35,36], we reasoned that salt, rather than acid, can be used as a chemically mild quencher of NTPase activities. Here we have combined 1) mild enzyme activity quench with $\mathrm{NaCl}$ rather than acid, 2) 
precipitation of true $\mathrm{P}_{i}$ as a $\mathrm{Ca}^{2+}$ salt to separate it from all OPCs prior to analysis, and 3) the use of ascorbate to reduce the phosphomolybdate complex to a deep blue color with increased color stability and sensitivity to $\mathrm{P}_{i}$ in order to create a simple and precise way to measure enzymatic nucleotide hydrolysis that is fully compatible with the nitrogenase assay requirements (i.e., ATP-regeneration system). It is also applicable to the study of other NTPases, as demonstrated here by the quantification of the GTPase activity of elongation factor G (EF-G). This assay has the potential to replace the use of both HPLC and radioactive nucleotide analyses for the determination of NTPase activity.

\section{MATERIALS AND METHODS}

Materials: Nucleotides were purchased from Roche Chemicals. All other chemicals were from Sigma-Aldrich unless otherwise noted.

Protein purification: Nitrogenase component proteins were purified from Azotobacter vinelandii as described previously [9]. The FeP and MoFeP had specific activities of 1600-2000 and 2200$2600 \mathrm{nmol} \mathrm{C}_{2} \mathrm{H}_{4} \mathrm{~min}^{-1} \mathrm{mg}^{-1}$ protein, respectively. $70 \mathrm{~S}$ ribosome was purified from $E$. coli MRE 600 cells as reported previously [37], except that cells were lysed at 16,000 psi with a microfluidizer. EF-G was purified from E. coli BL21-DE3 cells via the IMPACT method, as reported previously [38].

Nitrogenase activity assays: Nitrogenase activity assays were conducted anaerobically under an Ar atmosphere in an aqueous solution containing $0.2 \mu \mathrm{M}$ MoFeP, $2.0 \mu \mathrm{M} \mathrm{FeP}, 50 \mathrm{mM}$ Tris $(\mathrm{pH}$ 8.0), $60 \mathrm{mM} \mathrm{NaCl}, 5 \mathrm{mM} \mathrm{Na}_{2} \mathrm{ATP}, 5 \mathrm{mM} \mathrm{MgCl}_{2}, 30 \mathrm{mM} \mathrm{PC}, 0.00125 \mathrm{mg} / \mathrm{mL}$ creatine kinase, 6.5 $\mathrm{mM} \mathrm{Na}_{2} \mathrm{~S}_{2} \mathrm{O}_{4}$, and 0.072 atm $\mathrm{C}_{2} \mathrm{H}_{2}$ in a final volume of $1.16 \mathrm{~mL}$. Sealed 14-mL vials containing all components except FeP, MoFeP, $\mathrm{Na}_{2} \mathrm{~S}_{2} \mathrm{O}_{4}$, and $\mathrm{C}_{2} \mathrm{H}_{2}$ were made anaerobic on a Schlenk line. After solutions were made anaerobic, a $1.0 \mathrm{M} \mathrm{Na}_{2} \mathrm{~S}_{2} \mathrm{O}_{4}$ solution in $1.0 \mathrm{M}$ Tris base was prepared anaerobically and added to each vial to a final $\mathrm{Na}_{2} \mathrm{~S}_{2} \mathrm{O}_{4}$ concentration of $6.5 \mathrm{mM}$. Next, $1.0 \mathrm{~mL} 1 \mathrm{~atm} \mathrm{C}_{2} \mathrm{H}_{2}$ was transferred to each vial. After MoFeP was added to each vial, vials were shaken at $30^{\circ} \mathrm{C}$. The enzymatic reactions were initiated by the addition of FeP and terminated with $0.30 \mathrm{~mL}$ of $5 \mathrm{M} \mathrm{NaCl}$ after 10 minutes. Protein concentrations were determined via $\mathrm{Fe}$ chelation in $6.4 \mathrm{M}$ guanidine hydrochloride by 2,2-bipyridine using an extinction coefficient of $8650 \mathrm{M}^{-1} \mathrm{~cm}^{-1}$ at $522 \mathrm{~nm}$ [9].

Quantification of $\mathrm{C}_{2} \mathrm{H}_{2}$ and $\mathrm{CH}_{4}$ formed by nitrogenase: The amount of $\mathrm{e}^{-}$transferred to product by nitrogenase was determined by quantifying the amount $\mathrm{C}_{2} \mathrm{H}_{4}$ evolved with gas chromatography (GC); $\mathrm{CH}_{4}$ was also measured by $\mathrm{GC}$ in reactions containing $\mathrm{CN}^{-}$. Briefly, 50 $\mu \mathrm{L}$ aliquots of headspace from quenched reaction vials were injected into an SRI 8610C GC at 
$150^{\circ} \mathrm{C}$ containing an alumina column (Alltech) and a flame induction detector. $\mathrm{C}_{2} \mathrm{H}_{4}$ (Airgas) was used to generate the standard curve before sample analysis each day. For assay solutions that contained $\mathrm{NaCN}$, aliquots of a $100 \mathrm{mM} \mathrm{NaCN}$ stock solution were added to vials before degassing and salt concentrations were adjusted accordingly.

Quantification of $P_{\mathrm{i}}$ formation during nitrogenase turnover: ATP hydrolysis was monitored through the quantification of released $\mathrm{P}_{i}$ during the enzymatic reaction. After product formation was measured by GC, $500 \mu \mathrm{L}$ of each assay solution was removed and added to $800 \mu \mathrm{L}$ of a solution containing $200 \mathrm{mM} \mathrm{CaCl}_{2}$ and $50 \mathrm{mM}$ Tris ( $\mathrm{pH} \mathrm{8.0).} \mathrm{Solutions} \mathrm{were} \mathrm{mixed} \mathrm{and}$ centrifuged for $5 \mathrm{~min}$ at $13,000 \mathrm{~g}$. Because the force of pipetting could rupture the soft, white pellet, an aliquot of $1.2 \mathrm{~mL}$ of the supernatant fraction was removed, leaving $0.1 \mathrm{~mL}$ remaining in the tube with the precipitate, and $1.0 \mathrm{~mL}$ deionized (DI) $\mathrm{H}_{2} \mathrm{O}$ was added to the tube. Solutions were centrifuged for an additional $5 \mathrm{~min}$ at $13,000 \mathrm{~g}$. An aliquot of $1.0 \mathrm{~mL}$ of the supernatant fraction was removed, leaving $0.1 \mathrm{~mL}$ remaining in the tube with the precipitate, and $1.0 \mathrm{~mL} \mathrm{DI}$ $\mathrm{H}_{2} \mathrm{O}$ was again added to the tube. This process was repeated for a total of four centrifugation steps. The white pellet was then resuspended in a $1.0 \mathrm{~mL}$ solution of $0.2 \mathrm{M} \mathrm{HCl}$, and $100 \mu \mathrm{L}$ of

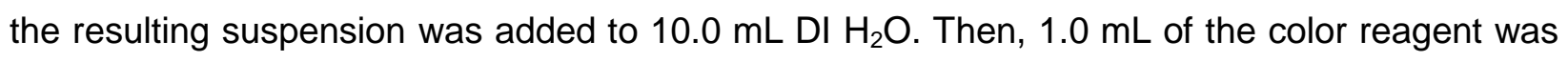
added. The method of Strickland and Parsons [39] was used for the preparation of the color reagent, which contained $4.9 \mathrm{mM}$ ammonium molybdate, $61 \mathrm{mM}$ ascorbate, and $0.42 \mathrm{mM}$ potassium antimonyl tartrate in $1.2 \mathrm{M}$ sulfuric acid. Absorbance of the blue solutions was measured at $885 \mathrm{~nm}$ after $1 \mathrm{~h}$ using an Agilent $8453 \mathrm{UV}$-visible spectrophotometer.

Quantification of GTPase activity of EF-G through the measurement of released $P_{\mathrm{i}}$ : Steady-state GTP hydrolysis by EF-G was measured in reaction mixtures containing activated $70 \mathrm{~S}$ ribosome $(0.2 \mu \mathrm{M}), 5 \mathrm{mM} \mathrm{Na}{ }_{2} \mathrm{GTP}, 20 \mathrm{mM}$ Hepes (pH 7.6), $6 \mathrm{mM} \mathrm{MgCl}, 150 \mathrm{mM} \mathrm{NH} \mathrm{Cl}_{4}, 4 \mathrm{mM}$ 2mercaptoethanol and varying concentrations of EF-G $(0-9 \mu \mathrm{M})$ in a total volume of $200 \mu \mathrm{L}$. Activity assays were conducted for 30-90 minutes in 1.7-mL Eppendorf tubes at room temperature and quenched by adding $80 \mu \mathrm{L}$ of $5 \mathrm{M} \mathrm{NaCl}$. Appropriate controls were carried out to ensure the rate of product formation was linear over the entire course of each assay and that the $\mathrm{NaCl}$ quench was as effective as routine quenching of EF-G activity with SDS. GTP hydrolysis was measured as $\mathrm{P}_{i}$ released as described above for nitrogenase but with the following modifications: $180 \mu \mathrm{L}$ quenched sample was mixed with $120 \mu \mathrm{L}$ of $400 \mathrm{mM} \mathrm{CaCl}_{2}$ in $100 \mathrm{mM}$ Tris ( $\mathrm{pH}$ 8.0) followed by $80 \mu \mathrm{L}$ of $100 \mathrm{mM} \mathrm{K} \mathrm{CO}_{3}$ in $100 \mathrm{mM}$ Tris (pH 8.0). $\mathrm{K}_{2} \mathrm{CO}_{3}$ was added to precipitate $\mathrm{CaCO}_{3}$ and increase the size of the white pellet. All trials were conducted at least in triplicate, and the error bars represent \pm 1 standard deviation. Data were fit to the Michaelis-Menten equation for enzyme kinetics using Prism. 
Quantification of GTPase activity of EF-G through the measurement of ${ }^{32} P_{\mathrm{i}}$ formed: Steady-state GTP hydrolysis by EF-G was measured in reactions containing, in a final volume of $50 \mu \mathrm{L}$, activated $70 \mathrm{~S}$ ribosome $(0.2 \mu \mathrm{M}), 2 \mathrm{mM} \mathrm{Na}{ }_{2} \mathrm{GTP}$ (trace ${ }^{32} \mathrm{P}-\gamma$-GTP, specific activity 12.5 $\mathrm{Ci} / \mathrm{mmol}$ ), $20 \mathrm{mM}$ Hepes (pH 7.6), $6 \mathrm{mM} \mathrm{MgCl}_{2}, 150 \mathrm{mM} \mathrm{NH}_{4} \mathrm{Cl}, 4 \mathrm{mM}$ 2-mercaptoethanol, and varying concentrations of EF-G $(0-9 \mu \mathrm{M})$. Assays were conducted in 1.7-mL Eppendorf tubes at room temperature. 3- $\mu \mathrm{L}$ aliquots were withdrawn at different time points and quenched with $1 \mu \mathrm{L}$ of $5 \%$ SDS. $1-\mu \mathrm{L}$ aliquots of the quenched solutions were spotted on cellulose thin-layer chromatography (TLC) plates and developed in $0.5 \mathrm{M} \mathrm{KH}_{2} \mathrm{PO}_{4}(\mathrm{pH} 3.5)$. The amount of ${ }^{32} \mathrm{P}_{i}$ formed was quantified using a phosphorimager. The initial velocities were plotted versus [EF-G] and fit to the Michaelis-Menten equation for enzyme kinetics using Prism. All trials were conducted at least in triplicate, and the error bars represent \pm 1 standard deviation. [Note: we used ${ }^{32} \mathrm{P}-\gamma$-GTP, which is hydrolyzed to ${ }^{32} \mathrm{P}_{i}$ and non-radioactive GDP. We monitor the formation of ${ }^{32} P_{i}$ by TLC].

\section{RESULTS AND DISCUSSION}

Development of the colorimetric assay for true $P_{\mathrm{i}}$ released: In addition to the conversion of $\mathrm{N}_{2}$ into $\mathrm{NH}_{3}$ (Equation 1), nitrogenase is also capable of reducing other substrates by multiples of 2 $e^{-}$, such as $\mathrm{C}_{2} \mathrm{H}_{2}$ to $\mathrm{C}_{2} \mathrm{H}_{4}$ [40]. The ATP requirement of nitrogenase is independent of the substrate being reduced [41]. In some cases, however, site-directed mutants and smallmolecule inhibitors have been shown to cause uncoupling of ATP hydrolysis from productive ET, significantly elevating the number of ATP molecules that must be hydrolyzed for the transfer of $2-\mathrm{e}^{-}\left(\mathrm{ATP} / 2 \mathrm{e}^{-}\right)$above the theoretical value of 4 [42-44]. While ET by nitrogenase is routinely measured by GC, to monitor the 2- $\mathrm{e}^{-}$reduction of $\mathrm{C}_{2} \mathrm{H}_{2}$ to $\mathrm{C}_{2} \mathrm{H}_{4}$, ATP hydrolysis by nitrogenase has historically been much more difficult to measure due to the complex, dynamic nature of the nitrogenase activity assay components.

Colorimetric determination of $\mathrm{P}_{i}$ released initially seemed to us the simplest, quickest, and least expensive method to quantify ATP hydrolysis by nitrogenase. Figure 1, however, highlights the difficulty in $\mathrm{P}_{i}$ quantification that occurs when $\mathrm{P}_{i}$ is in a complex mixture containing OPCs. Standard solutions of 0-20 $\mu \mathrm{M} \mathrm{P}_{i}$ made in $\mathrm{DI}_{2} \mathrm{H}_{2} \mathrm{O}$ turned blue when mixed with the color reagent containing ammonium molybdate, ascorbate, and potassium antimonyl tartrate in sulfuric acid (Figure 1A) [39]. However, when these standard solutions were instead made up in the nitrogenase activity assay matrix, which includes $30 \mathrm{mM} \mathrm{PC}$ and $5 \mathrm{mM}$ MgATP, both of which are OPCs, all solutions turned dark blue (Figure 1B), demonstrating that OPCs are susceptible to acid-catalyzed hydrolysis at low $\mathrm{pH}$. This process releases $\mathrm{P}_{i}$ and causes a 
dramatic increase in the effective concentration of $\mathrm{P}_{i}$ available to complex with molybdic acid. When we instead added an excess of $\mathrm{Ca}^{2+}$ to the $\mathrm{P}_{i}$ standard solutions containing OPCs (prior to mixing $P_{i}$ with the acidic color reagent), a white precipitate formed (Figure $1 \mathrm{C}$ ) wherein the true $\mathrm{P}_{i}$ is sequestered while OPC-associated $P_{\mathrm{i}}$ remains in the supernatant fraction. After removing the supernatant fraction and resuspending the precipitate in weak acid $(\sim 0.2 \mathrm{M} \mathrm{HCl})$, the color development of these $\mathrm{P}_{i}$ standards (Figure 1D) matched that of the $\mathrm{P}_{i}$ standards made in $\mathrm{DI} \mathrm{H}_{2} \mathrm{O}$ (Figure $\left.1 \mathrm{~A}\right)$.

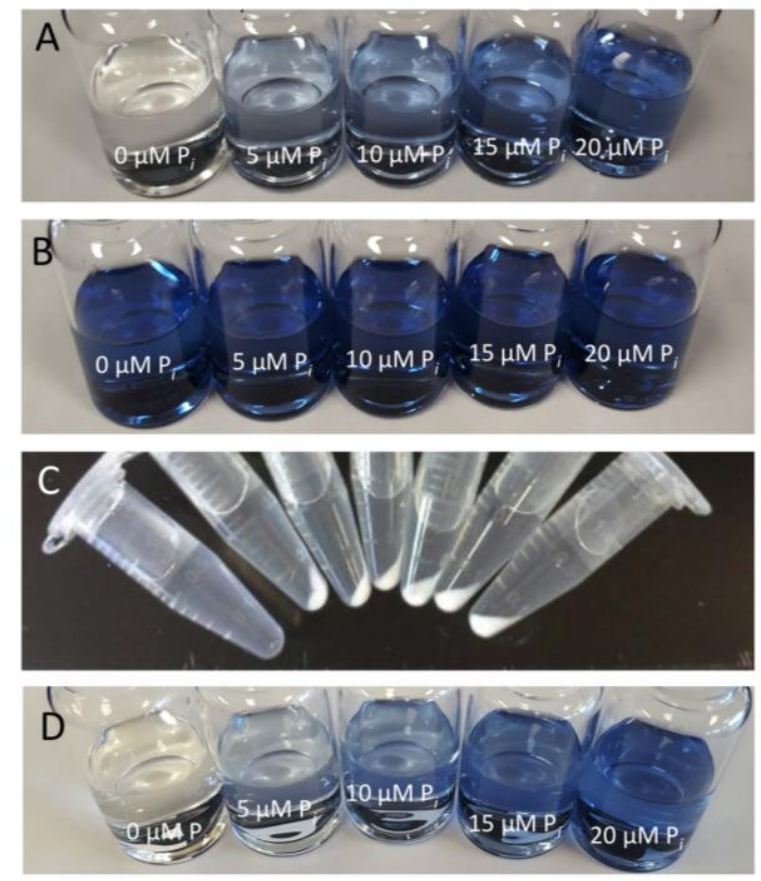

Figure 1. A. Blue phosphomolybdate complex formed from reaction of the molybdic acid color reagent with 0-4 mM $\mathrm{P}_{i}$ standard solutions in $\mathrm{DI}_{2} \mathrm{O}$ diluted to a final concentration of $0-20 \mu \mathrm{M} \mathrm{P}_{i}$, with increasing concentration from left to right. B. Blue phosphomolybdate complex formed from reaction of the molybdic acid color reagent with 0-4 mM $\mathrm{P}_{i}$ standard solutions in a mock nitrogenase activity assay solution containing $50 \mathrm{mM}$ Tris $(\mathrm{pH} 8.0), 30 \mathrm{mM}$ phosphocreatine, and $5 \mathrm{mM} \mathrm{MgATP}$ diluted to a final concentration of $0-20 \mu \mathrm{M} \mathrm{P}$, with increasing concentration from left to right. C. Solutions containing $0-4 \mathrm{mM} \mathrm{P} i$ after addition of excess $\mathrm{CaCl}_{2}$ and centrifugation. D. Blue phosphomolybdate complex formed from reaction of the molybdic acid color reagent with the 0-4 mM $\mathrm{P}_{i}$ standard solutions shown in $\mathrm{C}$ after the supernatant fraction is removed and precipitate is resuspended in weak acid. These solutions have been diluted to a final concentration of 0-20 $\mu \mathrm{M} \mathrm{P}$, with increasing concentration from left to right.

Next, we measured the rate of the blue phosphomolybdate complex formation. The absorbance of a $\mathrm{P}_{i}$ standard solution, when made up in a complex matrix containing an excess of OPCs, continues to increase with time due to continuous release of labile $\mathrm{P}_{i}$ from OPCs (Figure 2A). In contrast, when true $\mathrm{P}_{i}$ is separated from OPCs by precipitation with $\mathrm{Ca}^{2+}$ ahead of the addition of the acidic color reagent, the blue color stabilizes after about $1 \mathrm{~h}$ (Figure 2A), 
since no OPCs remain in solution to release additional $P_{i}$. Figure $2 B$ shows that standard curves of $\mathrm{P}_{i}$ diluted to a final concentration of $0-20 \mu \mathrm{M} \mathrm{P}$ made in $\mathrm{DI}_{2} \mathrm{H}_{2} \mathrm{O}$ (pictured in Figure $1 \mathrm{~A}$ ) and those made in the nitrogenase activity assay matrix, which includes a large excess of OPCs, (pictured in Figure 1D) overlay well when $\mathrm{P}_{i}$ is first precipitated as a $\mathrm{Ca}^{2+}$ salt. These experiments firmly establish that the $\mathrm{Ca}^{2+}$ precipitation procedure is effective at separating labile OPCs from true $P_{i}$. Furthermore, quantitative recovery of $P_{i}$ is achieved by this procedure, since there is no change in the absorbance of $\mathrm{P}_{i}$ standards made in $\mathrm{DI}_{2} \mathrm{O}$ whether or not the $\mathrm{Ca}^{2+}$ precipitation step is used. $P_{i}$ was quantitatively recovered whenever the white precipitate was visible. This initially required a minimum of $1 \mu \mathrm{mol} \mathrm{P}_{i}$ and an excess of $\mathrm{Ca}^{2+}$. However, additional salts (i.e. $\mathrm{K}_{2} \mathrm{CO}_{3}$ ) could be added to co-precipitate insoluble $\mathrm{Ca}^{2+}$ salts, thereby increasing the size of the white pellet. Using this technique, as little as $100 \mathrm{nmol} \mathrm{P}_{i}$ was routinely pelleted and quantitatively recovered.
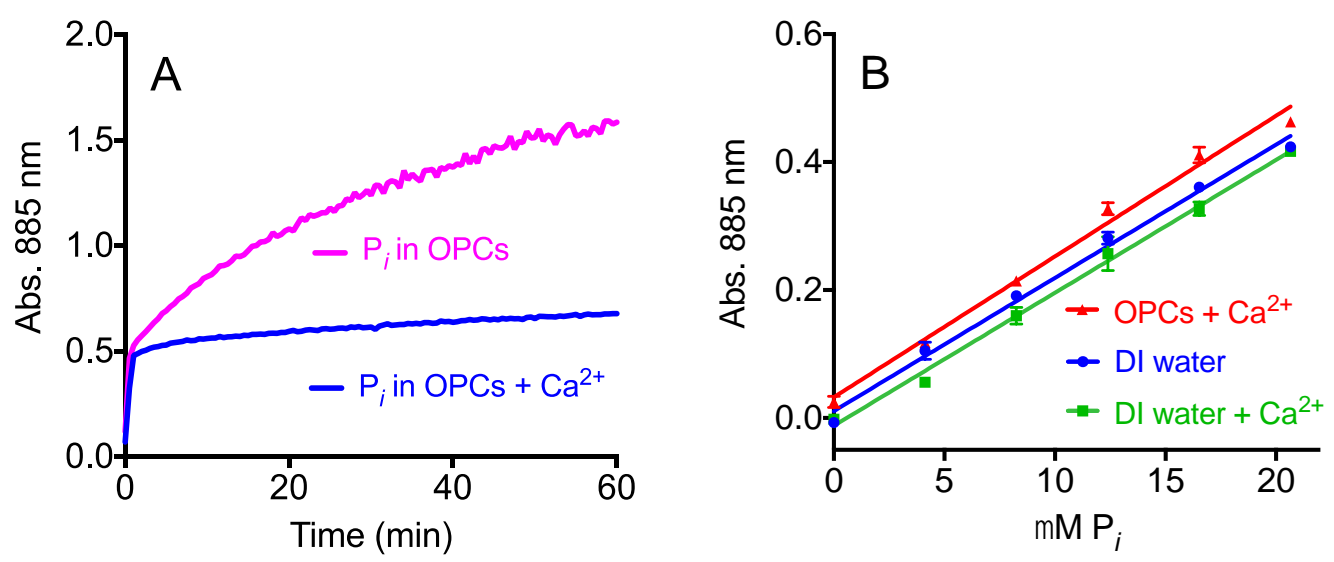

Figure 2. A. Time course for the blue phosphomolybdate complex development monitored by absorbance at $885 \mathrm{~nm}$ of $\mathrm{P}_{i}$ standard solutions in a matrix containing OPCs with (blue) and without (pink) the $\mathrm{Ca}^{2+}$ precipitation step to sequester true $\mathrm{P}_{i}$ and separate it from OPCs. B. Standard curves in triplicate of $\mathrm{P}_{i}$ standards in $\mathrm{DI} \mathrm{H}_{2} \mathrm{O}$ (blue; $\mathrm{y}=$ $(0.021 \pm 0.001) x+(0.011 \pm 0.011))$, in $\mathrm{DI} \mathrm{H}_{2} \mathrm{O}$ and treated with the $\mathrm{Ca}^{2+}$ precipitation step (green; $\mathrm{y}=(0.021 \pm 0.001)$ $x-(0.012 \pm 0.001))$, and in the nitrogenase activity assay matrix, which contains and excess of OPCs, but that has been treated with the $\mathrm{Ca}^{2+}$ precipitation step (red; $\mathrm{y}=(0.022 \pm 0.001) \mathrm{x}+(0.032 \pm 0.013)$ ).

Application of method for measuring true $P_{\mathrm{i}}$ to quantify ATPase activity: To assess the ability of our method to quantify ATP hydrolysis during nitrogenase turnover, we measured the ATP/2 $\mathrm{e}^{-}$ ratio for wild-type (wt) nitrogenase under standard assay conditions and compared our measurements to published results. The ATP/2 $\mathrm{e}^{-}$ratio for wt nitrogenase should approach 4 when the activity assay is performed at $30^{\circ} \mathrm{C}$ and $\mathrm{Na}_{2} \mathrm{~S}_{2} \mathrm{O}_{4}$ is used as the external reducing agent [45], as demonstrated by Eq. 1 . Experimentally, ratios of 4-5 are typically measured, but 
with standard deviations that are often not reported or can be greater than the mean [43-47]. First, we quenched our nitrogenase activity assays with $5 \mathrm{M} \mathrm{NaCl}$ rather than concentrated acid, base, chelator, or detergent. We quantified the amount of $\mathrm{e}^{-}$productively transferred to substrate by wt nitrogenase by quantifying the amount of $\mathrm{C}_{2} \mathrm{H}_{4}$ formed from $\mathrm{C}_{2} \mathrm{H}_{2}$ using GC. Then, we added $\mathrm{CaCl}_{2}$ to the assay solutions to capture released $\mathrm{P}_{i}$ in a white precipitate. We centrifuged the assay solutions, removed the supernatant fraction, resuspended the white pellet, and added an aliquot of each activity assay solution to the acidic color reagent. After measuring the absorbance of these solutions at $885 \mathrm{~nm}$, our method yielded an ATP/2 $\mathrm{e}^{-}$value of $4.8 \pm 0.3$ with a percent relative standard deviation (\%RSD) of $5.3 \%$ (Table 1). Thus, our method is able to reproduce the accepted $\mathrm{ATP} / 2 \mathrm{e}^{-}$literature value in the presence of the regeneration system, which contains a large excess of OPCs, (30 mM PC, $5 \mathrm{mM} \mathrm{MgATP}, 0.125 \mathrm{mg} / \mathrm{mL}$ creatine kinase) with a substantial increase in precision. This will greatly aid in the analysis of slight differences in the activities of site-directed nitrogenase mutants.

As an additional test, we also measured the $\mathrm{ATP} / 2 \mathrm{e}^{-}$ratio for wt nitrogenase under conditions known to cause uncoupling of ATP hydrolysis from ET. $\mathrm{CN}^{-}$is known to inhibit nitrogenase activity by uncoupling the hydrolysis of ATP from productive ET to substrate. The $\mathrm{ATP} / 2 \mathrm{e}^{-}$increases with increasing $\left[\mathrm{CN}^{-}\right]$and plateaus at about 18 when $\left[\mathrm{CN}^{-}\right] \geq 80 \mu \mathrm{M}[42]$. We chose to measure the ATP/2 $\mathrm{e}^{-}$for wt nitrogenase proteins in the presence of $5 \mathrm{mM} \mathrm{NaCN}$ at $\mathrm{pH}$ 8.0, so the effective $\left[\mathrm{CN}^{-}\right]$would be much larger than $80 \mu \mathrm{M}$. Though $\mathrm{CN}^{-}$is a reversible inhibitor of nitrogenase activity, $\mathrm{HCN}$ is a substrate of nitrogenase. Thus, in order to measure the amount of $\mathrm{e}^{-}$transferred to product, we measured both the $\mathrm{C}_{2} \mathrm{H}_{4}$ formed from 2- $\mathrm{e}^{-}$reduction of $\mathrm{C}_{2} \mathrm{H}_{2}$ and the $\mathrm{CH}_{4}$ formed from 6-e reduction of $\mathrm{HCN}$ to $\mathrm{CH}_{4}$ and $\mathrm{NH}_{3}$. As expected, the ratio of $\mathrm{ATP} / 2 \mathrm{e}^{-}$under these conditions, $16 \pm 1.1$, as measured by our $\mathrm{NaCl} / \mathrm{Ca}^{2+} / \mathrm{P}_{i}$ assay, lies within the range of previously reported values (Table 1) [42].

Table 1. ATP $/ 2 \mathrm{e}^{-}$values for wt nitrogenase under standard conditions and in the presence of $5 \mathrm{mM} \mathrm{NaCN}$ at $\mathrm{pH} 8.0$

\begin{tabular}{|c|c|c|}
\hline & ATP/2e $^{-}$(in literature) & ATP/2e $^{-}$(this work) \\
\hline WT nitrogenase, & $4-5(\% R S D s>100 \%$ & $4.8 \pm 0.3(5.3 \%$ RSD) \\
standard conditions & reported) & \\
\hline $\begin{array}{c}\text { WT nitrogenase with 5 } \\
\text { mM NaCN at pH 8.0 }\end{array}$ & $\begin{array}{c}17-18(\% R S D s \text { not } \\
\text { reported) }\end{array}$ & \\
\hline
\end{tabular}

Application of method for measuring $P_{\mathrm{i}}$ to quantify GTPase activity: As an independent validation of our $\mathrm{NaCl} / \mathrm{Ca}^{2+} / \mathrm{P}_{i}$ assay, we measured ribosome-dependent GTP hydrolysis by EFG. EF-G is a ribosome factor that participates in protein synthesis. Translocation of mRNA and 
tRNA along the ribosome is coupled to the binding and hydrolysis of GTP by EF-G [48]. In order to interrogate how the hydrolysis of GTP is coupled to the efficient synthesis of proteins, it is crucial to precisely measure GTP hydrolysis by wt EF-G and site-directed mutants. An established method for measuring GTP hydrolysis by EF-G requires the use of radiolabeled GTP [49]. Each activity assay is initially spiked with ${ }^{32} \mathrm{P}-\mathrm{y}$-GTP. After the enzyme activity is quenched, ${ }^{32} \mathrm{P}-\mathrm{y}$-GTP and ${ }^{32} \mathrm{P}_{i}$ are separated by TLC and the ratio of radioactivity counts is used to extrapolate the extent of hydrolysis. While this assay offers a substantially higher sensitivity than colorimetric measurements, radiolabeled nucleotides are expensive, hazardous and have a short shelf life.

Table 2. Steady-state Michaelis-Menten kinetic parameters for 70 S ribosome-dependent GTP hydrolysis by EF-G

\begin{tabular}{|c|c|c|}
\hline & $K_{\mathrm{m}}(\mu \mathrm{M})$ & $k_{\text {cat }}\left(\mathrm{s}^{-1}\right)$ \\
\hline${ }^{32} \mathrm{P}-\mathrm{\gamma}-\mathrm{GTP}$ method (this work) & $8.7 \pm 0.8$ & $5.0 \pm 0.3$ \\
\hline $\mathrm{NaCl} / \mathrm{Ca}^{2+} / \mathrm{P}_{i}$ method (this work) & $9.4 \pm 3.5$ & $3.1 \pm 0.7$ \\
\hline
\end{tabular}

To establish that our method for measuring ATPase activity was also applicable to GTPase activity measurements, we determined the steady-state Michaelis-Menten parameters for ribosome-dependent GTP hydrolysis by EF-G using two techniques. First, we measured GTP hydrolysis using the established ${ }^{32} \mathrm{P}-\mathrm{y}$-GTP method, and we determined the $k_{\text {cat }}$ for ribosome-dependent GTP hydrolysis to be $5.0 \pm 0.3 \mathrm{~s}^{-1}$ and the $K_{\mathrm{m}}$ to be $8.7 \pm 0.8 \mu \mathrm{M}$ (Table 2). We subsequently measured 70 S ribosome-dependent GTP hydrolysis by EF-G under the same reaction conditions using our colorimetric method. Like nitrogenase assays, these EF-G activity assays were quenched with $5 \mathrm{M} \mathrm{NaCl}$ rather than acid or detergent. Using this method, we determined the $k_{\text {cat }}$ for ribosome-dependent GTP hydrolysis to be $3.1 \pm 0.7 \mathrm{~s}^{-1}$ and the $K_{\mathrm{m}}$ to be $9.4 \pm 3.5 \mu \mathrm{M}$. It is important to note that though these $k_{\text {cat }}$ values lie within two standard deviations of one another, both fall well within the range of previously reported $k_{\text {cat }}$ values for ribosome-dependent GTP hydrolysis by EF-G [36,49,50]. Additionally, while the $K_{\mathrm{m}}$ values determined by these techniques are slightly higher than what has been reported previously, which can be explained by the inherent preparation-to-preparation variance in ribosome purity among laboratories [36,51], they are within one standard deviation of one another. Figure 3 shows the Michaelis-Menten curves obtained in this work. Because the standard ${ }^{32} \mathrm{P}-\mathrm{y}$-GTP assay and our new $\mathrm{NaCl} / \mathrm{Ca}^{2+} / \mathrm{P}_{i}$ method yielded overall similar steady-state kinetic parameters, while achieving a decrease in cost, hazard, and time, our method is well suited to assess changes in the GTP hydrolysis activity of EF-G, for example, due to mutagenesis. 


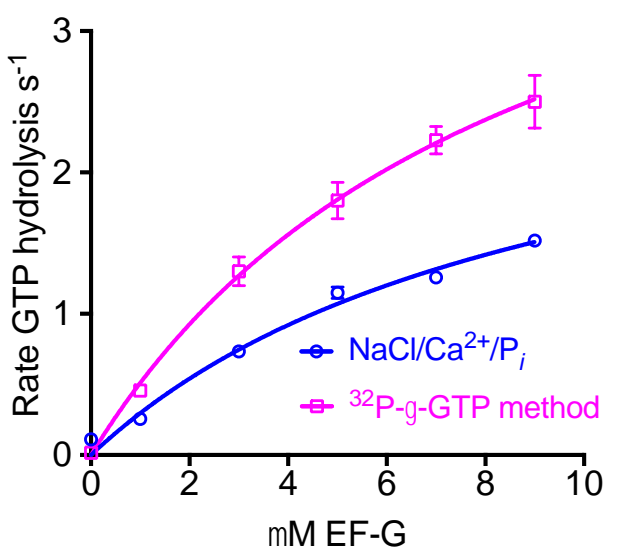

Figure 3. Michaelis-Menten curves show the rate of $70 \mathrm{~S}$ ribosome-dependent GTP hydrolysis by EF-G as a function of $[E F-G]$. Data obtained using our $\mathrm{NaCl} / \mathrm{Ca}^{2+} / \mathrm{P}_{i}$ method for measuring nucleotide hydrolysis is shown in blue and compared to data obtained using the standard radiolabeled nucleotide technique, shown in pink. Error bars represent \pm 1 s.d.

\section{CONCLUSIONS}

We have presented here an improved assay for nucleotide hydrolysis through the determination of true $\mathrm{P}_{i}$ in the presence of labile OPCs that is applicable to ATPases as well as GTPases. Compared to established methods for measuring nucleotide hydrolysis, this method has minimal requirements for specialized instrumentation, requiring only a single-beam UV-vis spectrophotometer, utilizes non-hazardous and inexpensive reagents, and is at least as precise as standard available techniques. The major limitation of this assay is the amount of $P_{i}$ released that is required for reliable quantification. Currently, our method requires a minimum of $100 \mathrm{nmol}$ $\mathrm{P}_{i}$ for precise measurements. Further exploration with insoluble $\mathrm{Ca}^{2+}$ salts could lead to strategies to lower this minimum requirement.

\section{ACKNOWLEDGMENTS}

This work was funded by an NIH grant (GM099813) and a Frasch Foundation Award (735HF12) to F.A.T. C.P.O. is the recipient of a postdoctoral fellowship from the USDA (2015-6701222895).

\section{References}

[1] H.R. Bourne, D.A. Sanders, F. McCormick, The GTPase superfamily - conserved structure and molecular mechanism, Nature 349 (1991) 117-127.

[2] M.P. Mayer, B. Bukau, Hsp70 chaperones: Cellular functions and molecular mechanism, Cell. Mol. Life Sci. 62 (2005) 670-684. 
[3] T. Ogura, A.J. Wilkinson, AAA+ superfamily ATPases: common structure-diverse function, Genes Cells 6 (2001) 575-597.

[4] M. Cashel, R.A. Lazzarini, B. Kalbacher, An improved method for thin-layer chromatography of nucleotide mixtures containing 32 P-labeled orthophosphate, J. Chromatogr. A 40 (1969) 103-109.

[5] V. Stocchi, L. Cucchiarini, M. Magnani, L. Chiarantini, P. Palma, G. Crescentini, Simultaneous extraction and reverse-phase high-performance liquid chromatographic determination of adenine and pyridine nucleotides in human red blood cells, Anal. Biochem. 146 (1985) 118-124.

[6] E.S. Baginski, E. Epstein, B. Zak, Review of phosphate methodologies, Ann. Clin. Lab. Sci. 5 (1975) 399-416.

[7] S. Chifflet, A. Torriglia, R. Chiesa, S. Tolosa, A method for the determination of inorganic phosphate in the presence of labile organic phosphate and high concentrations of protein: application to lens ATPases, Anal. Biochem. 168 (1988) 1-4.

[8] F.A. Tezcan, J.T. Kaiser, J.B. Howard, D.C. Rees, Structural evidence for asymmetrical nucleotide interactions in nitrogenase, J. Am. Chem. Soc. 137 (2014) 146-149.

[9] C.P. Owens, F.E.H. Katz, C.H. Carter, M.A. Luca, F.A. Tezcan, Evidence for functionally relevant encounter complexes in nitrogenase catalysis, J. Am. Chem. Soc. 137 (2015) 1270412712 .

[10] J.B. Howard, D.C. Rees, Structural basis of biological nitrogen fixation, Chem. Rev. 96 (1996) 2965-2982.

[11] B.K. Burgess, D.J. Lowe, Mechanism of molybdenum nitrogenase, Chem. Rev. 96 (1996) 2983-3012.

[12] R.V. Hageman, R. Burris, Nitrogenase and nitrogenase reductase associate and dissociate with each catalytic cycle, Proc. Natl. Acad. Sci. U.S.A. 75 (1978) 2699-2702.

[13] L.C. Seefeldt, D.R. Dean, Role of nucleotides in nitrogenase catalysis, Acc. Chem. Res. 30 (1997) 260-266.

[14] W. Bulen, J. LeComte, The nitrogenase system from Azotobacter: two-enzyme requirement for N2 reduction, ATP-dependent H2 evolution, and ATP hydrolysis, Proc. Natl. Acad. Sci. U.S.A. 56 (1966) 979-986.

[15] M. Yates, R. Thorneley, D. Lowe, Nitrogenase of Azotobacter chroococcum: Inhibition by ADP of the reduction of oxidised Fe protein by sodium dithionite, FEBS Lett. 60 (1975) 89-93.

[16] B. Gao, Y. Emoto, L. Greene, E. Eisenberg, Nucleotide binding properties of bovine brain uncoating ATPase, J. Biol. Chem. 268 (1993) 8507-8513.

[17] K.J. Moore, M.R. Webb, J.F. Eccleston, Mechanism of GTP hydrolysis by p21N-ras catalyzed by GAP: Studies with a fluorescent GTP analog, Biochemistry 32 (1993) 7451-7459.

[18] S. Awasthi, J. Cheng, S.S. Singhal, M.K. Saini, U. Pandya, S. Pikula, J. BandorowiczPikula, S.V. Singh, P. Zimniak, Y.C. Awasthi, Novel function of human RLIP76: ATPdependent transport of glutathione conjugates and doxorubicin, Biochemistry 39 (2000) 93279334.

[19] L.C. Davis, S. Kotake, Regulation of nitrogenase activity in aerobes by Mg 2+ availability: an hypothesis, Biochem. Bioph. Res. Co. 93 (1980) 934-940.

[20] A.H. Ennor, Determination and preparation of n-phosphates of biological origin, Method Enzymol. 3 (1957) 850-861.

[21] W.E. Newton, M.J. Dilworth, Assays of nitrogenase reaction products, Nitrogen Fixation: Methods and Protocols (2011) 105-127. 
[22] C.H. Fiske, Y. Subbarow, The colorimetric determination of phosphorus, J. Biol. Chem. 66 (1925) 375-400.

[23] R. Van Noorden, B. Maher, R. Nuzzo, The top 100 papers, Nature 514 (2014) 550-553.

[24] H. Weil-Malherbe, R. Green, The catalytic effect of molybdate on the hydrolysis of organic phosphate bonds, Biochem. J. 49 (1951) 286-292.

[25] P. Ottolenghi, The reversible delipidation of a solubilized sodium-plus-potassium iondependent adenosine triphosphatase from the salt gland of the spiny dogfish, Biochem. J. 151 (1975) 61-66.

[26] L.C. Mokrasch, Spectrophotometric determination of phosphate in the presence of highly labile phosphorus compounds, Anal. Chem. 33 (1961) 432-434.

[27] J. Lecocq, G. Inesi, Determination of inorganic phosphate in the presence of adenosine triphosphate by the molybdo-vanadate method, Anal. Biochem. 15 (1966) 160-163.

[28] B. Repen, E. Schneider, U. Alexiev, Optimization of a malachite green assay for detection of ATP hydrolysis by solubilized membrane proteins, Anal. Biochem. 426 (2012) 103-105.

[29] I.C. Berenblum, E. , An improved method for the colorimetric determination of phosphate, Biochem. J. 32 (1938) 295-298.

[30] S.M.P. Mozersky, J. D.; Kolman, S. D., Micromethod for determination of orthophosphate in presence of adenosine triphosphate after deproteilnization with trichloroacetate buffer, Anal. Chem. 40 (1968) 788-791.

[31] C.H. Fiske, Y. Subbarow, Phosphocreatine, J. Biol. Chem. 81 (1929) 629-679.

[32] F.T. Lipmann, L. C., Acetyl phosphate: chemistry, determination, and synthesis, J. Biol. Chem. 153 (1944) 571-582.

[33] K. Seraydarian, A. Wallner, R.J. Guillory, W.F.H. Mommaerts, Estimation of true inorganic phosphate content of frog sartorious muscle, J. Biol. Chem. 236 (1961) 2071-2075.

[34] T.L. Deits, J. Howard, Effect of salts on Azotobacter vinelandii nitrogenase activities. Inhibition of iron chelation and substrate reduction, J. Biol. Chem. 265 (1990) 3859-3867.

[35] M. Lorenz, K.C. Holmes, The actin-myosin interface, Proc. Natl. Acad. Sci. U.S.A. 107 (2010) 12529-12534.

[36] G. Sander, G. Parlato, J.B. Crechet, K. Nagel, A. Parmeggiani, Regulation of turnover GTPase activity of elongation factor-G - 30-S-coupled and 30-S-uncoupled reactions coordinated effects of cations, $\mathrm{pH}$ and polyamines, Eur. J. Biochem. 86 (1978) 555-563.

[37] M.V. Rodnina, W. Wintermeyer, GTP consumption of elongation factor Tu during translation of heteropolymeric mRNAs, Proc. Natl. Acad. Sci. U.S.A. 92 (1995) 1945-1949.

[38] J.S.a.J. Feinberg, S., Ribose 2'-hydroxyl groups in the 5' strand of the acceptor arm of P-site tRNA are not essential for EF-G catalyzed translocation, RNA 12 (2006) 580-588.

[39] J.D.H. Strickland, T.R. Parsons, J.D.H. Strickland. A practical handbook of seawater analysis. Ottawa: Fisheries Research Board of Canada; 1972.

[40] R. Hardy, R. Burns, R. Holsten, Applications of the acetylene-ethylene assay for measurement of nitrogen fixation, Soil Biol. Biochem. 5 (1973) 47-81.

[41] G.D. Watt, A. Burns, Kinetics of dithionite ion utilization and ATP hydrolysis for reactions catalyzed by the nitrogenase complex from Azotobacter vinelandii, Biochemistry 16 (1977) 264270.

[42] J.B. Li, B. K.; Corbin, J. L., Nitrogenase reactivity: cyanide as substrate and inhibitor, Biochemistry 21 (1982) 4393-4402. 
[43] L.C. Seefeldt, Docking of nitrogenase iron- and molybdenum-iron proteins for electron transfer and MgATP hydrolysis: the role of arginine 140 and lysine 143 of the Azotobacter vinelandii iron protein., Protein Sci. 3 (1994) 2073-2081.

[44] C.-H. Kim, W.E. Newton, D.R. Dean, Role of the MoFe Protein. alpha.-Subunit Histidine195 Residue in FeMo-cofactor Binding and Nitrogenase Catalysis, Biochemistry 34 (1995) 2798-2808.

[45] G.D. Watt, W.A. Bulen, A. Burns, K. Lamonthadfield, Stoichiometry, ATP-2e values, and energy-requirements for reactions catalyzed by nitrogenase from Azotobacter-Vinelandii, Biochemistry 14 (1975) 4266-4272.

[46] L.C. Seefeldt, L.E. Mortenson, Increasing nitrogenase catalytic efficiency for MgATP by changing serine 16 of its Fe protein to threonine: use of Mn2+ to show interaction of serine 16 with Mg2+, Protein Sci. 2 (1993) 93-102.

[47] J.A.N. Erickson, A. C.; Johnson, J. L.; Truscott, S. M.; Gunn, A.; Nordmeyer, F. A.; Watt, G. D., Enhanced efficiency of ATP hydrolysis during nitrogenase catalysis utilizing reductants that form the all-ferrous redox state of the Fe protein, Biochemistry 38 (1999) 14279-14285.

[48] W. Wintermeyer, M.V. Rodnina, Translational elongation factor G: a GTP-driven motor of the ribosome, Essays Biochem. 35 (2000) 117-129.

[49] L.Á.-G. García-Ortega, E.; Gavilanes, J. G.; Martinez-del-Pozo, Á.; Joseph, S., Cleavage of the sarcin-ricin loop of 23S rRNA differentially affects EF-G and EF-Tu binding, Nucleic Acids Res. 38 (2010) 4108-4119.

[50] H.-S. Seo, S. Abedin, D. Kamp, D.N. Wilson, K.H. Nierhaus, B.S. Cooperman, EF-Gdependent GTPase on the ribosome. Conformational change and fusidic acid inhibition, Biochemistry 45 (2006) 2504-2514.

[51] A. Parmeggiani, G. Sander, Properties and regulation of the GTPase activities of elongation factors Tu and G, and of initiation factor 2, Mol. Cell. Biochem. 35 (1981) 129-158. 